\title{
Cost of Diabetes Mellitus Care among Patients attending selected Outpatient Clinics
}

\author{
Niraj Shrestha, ${ }^{1}$ Shyam Prasad Lohani, ${ }^{2}$ Mirak Raj Angdembe, ${ }^{3}$ Kreepa Bhattarai, ${ }^{4}$ Jyoti Bhattarai ${ }^{5}$ \\ ${ }^{1}$ maxPro, Lalitpur, ${ }^{2}$ Nobel College, Kathmandu, ${ }^{3}$ Central Institute of Science and Technology, Kathmandu, ${ }^{4}$ Kantipur Dental \\ College, Kathmandu, ${ }^{5}$ Metro Clinic, Kathmandu, Nepal.
}

\section{ABSTRACT}

Introduction: In developing countries diabetes mellitus affects economically productive age group; more often affecting the productive member of the family. The objective of the study was to estimate the direct and indirect cost of illness of patients with DM attending the selected outpatient clinics in Kathmandu Valley.

Methods: A cross-sectional study was carried out in four outpatient clinics in Kathmandu Valley among 227 diabetic patients selected purposively. It was conducted from July to September, 2010. An adapted and pretested semi structured questionnaire was administered to diabetic patients aged 20 to 60 years with a minimum of a year of illness.

Results: The mean total cost per visit by a diabetic patient to an outpatient clinic wasUS\$13.3 (95\% Cl: 11.70-14.92). Likewise the total cost incurred in the treatment and care of DM per month was US\$ 40.41 (95\% Cl: 36.38-44.45) and per annum was US\$ 445 (95\% Cl: 396.11 495.61). In addition, the study results also showed that with increase in total direct cost per annum the duration of illness also increases.

Conclusions: There is a high cost burden on the patient with DM visiting the selected private sector outpatient clinics.

Keywords: cost burden; diabetes mellitus; direct cost; indirect cost; treatment cost.

\section{INTRODUCTION}

In developing countries diabetes mellitus (DM) affects economically productive age group pushing the whole family into a vicious cycle of poverty and health related conditions. ${ }^{1}$ According to International Diabetes Federation (IDF), the world is estimated to have spent at least US\$376 billion to treat and prevent DM and it's complications in 2010 with each country spending between $5-13 \%$ of their health expenditure. ${ }^{2}$ In South Asia, the direct cost of DM management was US\$ 5 billion, while indirect costs totaled US $\$ 10$ billion. $^{1}$

People with DM are at an increased risk of developing long term complications such as amputation, retinopathy, cardiovascular disease, neuropathy, nephropathy and peripheral vascular disease..$^{3,4}$ They are heavy lifetime users of health resources, culminating into high cost. ${ }^{5}$ The study aimed to estimate the cost of illness of DM among patients attending selected outpatient clinics in Kathmandu Valley.

\section{METHODS}

It was a cross-sectional study carried out from July to September, 2010. A public hospital, a private hospital,

Correspondence: Mr. Niraj Shrestha, maxPro, Lalitpur, Nepal. Email: nirajshrestha44@gmail.com, Phone: 9841734431. 
and two polyclinicsone each in Kathmandu and Lalitpur were selected as the study sites. An NGO based DM clinic in Kathmandu was taken as the site for pre-testing the questionnaire.

In this study, 227 respondents aged 20-60 years with a minimum of a year of illness were purposively selected. Patients who were pregnant during the study period and those who were newly diagnosed (less than a year of illness) were not included in the study. A pre-tested semi-structured questionnaire was used for data collection, some portions of which were adapted from a similar study conducted in Karachi, Pakistan. ${ }^{6}$ The questionnaire was reviewed by a Nepali language expert who corrected grammatical errors (if any) in the questionnaire. Of the total respondents, 76 (34\%) attended public sector clinic while $151(67 \%)$ attended private sector clinics. The distribution of respondents in the four study sites: Site A: 76(34\%); Site B: 50(22\%); Site C: 55(24\%); Site D: 46(20\%).

Direct and indirect costs were calculated. Doctor's fee, laboratory investigation cost, medicine cost, traveling cost incurred during the current visit to the outpatient clinic from within or outside the valley and other costs (food cost, ticket price etc.) were the component items of direct cost per visit. In addition, cost incurred during the purchase of insulin (if using), reagent strip of the glucose meter (if using), medicine, supplementary food products (if using) and expenditure on physical exercise in places such as a gym or a yoga center (if visiting) were component items for the measurement of monthly expenditure. The yearly expenditure was calculated based on the per visit cost multiplied by average number of visits per annum and other components of monthly expenditure.

The indirect cost was calculated based on human capital approach. Consultation time, waiting time in the clinic, traveling time to the clinic, and lost work days were used to calculate the indirect cost. It was measured in terms of present earnings lost by that individual as a result of time invested in current visit to an outpatient clinic. It also incorporated lost earnings due to lost work days as a result of health hazard brought about by DM from April 14, 2010 (the first day of the year as per the Nepali calendar i.e. first Baishakh 2067 B.S) to the date of interview. The earning lost was calculated based on the respondents' monthly income.

The study did not incorporate intangible costs such as pain, anxiety and depression associated with the illness. It assumed time spent during doctor's consultation, waiting time and traveling time to the outpatient clinic as lost earning calculated in terms of wage rate per hour. The study assumed that same amount of money was spent during each visit made to the clinic throughout the year. It was not possible to verify and confirm the information provided with regards to cost incurred in the purchase of medicine, supplements, reagent strip used in glucose meter and insulin by cross checking with the medical case records and there lay prominent chances of introduction of recall bias. The study assumed housewife as employment status. The wage rates of the housewives were estimated using the minimum wage rate (Nepalese Rupees, NRs.4600 = US\$ 64) of Nepal in 2009.7

Data were entered and analyzed using the statistical package for social sciences (SPSS 17 for windows). In multivariate analysis, a weighted least square regression model was developed to assess the influence of duration of DM, number of co-morbidities and household income per month of the respondents on the criterion variable (total direct cost per year). The significance of the relationship between the predictors and criterion variable was tested through ANOVA test. Normality of distribution was tested using Kolmogorov Smirnov test.Ethical clearance for the study was obtained from the Institutional Review Board, Department of Public Health, Nobel College, Pokhara University. A verbal informed consent was taken from the respondents prior to interview. In addition, the names of the study sites were not disclosed for confidentiality.

\section{RESULTS}

In the study, majority i.e. 160 (70\%) respondents belonged to the age group of $46-60$ years. The mean age of the respondents was $49 \pm 7.8$ years, youngest being 26 years and oldest 60 years. There were 134 (59\%) male and 93 (41\%) female respondents. Only $28(12 \%)$ respondents permanently resided outside the valley. In the study, $202(89 \%)$ respondents had received formal education while $25(11 \%)$ of them had not. Majority, 81 (36\%)of the respondents were either employed in a public or a private sector organizationand $71(31 \%)$ were handling their own business. Nearly one fifth, $48(21 \%)$ of the respondents were housewives. In terms of wealth quintile, around $86 \%$ of the respondents fell within the category of lowest and second quintile with household income ranging from US\$ 41.67 to US\$ 819.44. The average monthly income of the respondent and total household income were found to be US\$ $323.57(95 \% \mathrm{Cl}: 277.70-369.44)$ and US\$494.6 (95\% Cl: 451.42-537.78) respectively.

Medicinal costs made up $80 \%$ of the total direct cost per visit (US\$11), followed by doctor's fee (35\%) and laboratory investigation (33\%) (Table 1). 
Shrestha et al. Cost of Diabetes Mellitus Care among Patients attending selected Outpatient Clinics

\begin{tabular}{|c|c|c|c|c|c|}
\hline Direct cost per visit & $\mathrm{N}$ & Min. & Max. & Mean (SD) & $95 \% \mathrm{Cl}$ for mean \\
\hline Doctor's fee & 151 & 2.50 & 5.16 & $3.92(75.10)$ & $3.77-4.08$ \\
\hline Medicinal cost & 118 & 0.41 & 166.67 & $9.02(1183.90)$ & $3.28-11.99$ \\
\hline Transport fare & 96 & 0.13 & 16.67 & $2.12(275.90)$ & $1.35-2.86$ \\
\hline Laboratory investigation cost & 211 & 0.69 & 41.67 & $3.68(455.80)$ & $2.82-4.53$ \\
\hline Other cost incurred & 85 & 0.27 & 2.01 & $0.37(21)$ & $0.31-0.43$ \\
\hline Total direct cost per visit & 227 & 0.41 & 72.08 & $11.24(816)$ & $9.77-12.72$ \\
\hline Indirect cost per visit & $\mathrm{N}$ & Min. & Max. & Mean (SD) & $95 \% \mathrm{Cl}$ for mean \\
\hline Waiting time in the clinic per visit & 227 & 0.08 & 6.00 & $0.70(0.60)$ & $0.60-0.77$ \\
\hline Consultation time per visit & 227 & 0.08 & 0.33 & $0.17(0.06)$ & $0.16-0.18$ \\
\hline Travel time to the clinic per visit & 227 & 0.17 & 2.00 & $0.61(0.38)$ & $0.56-0.66$ \\
\hline Lost time of the patient & 227 & 0.50 & 4.67 & $1.45(0.74)$ & $1.36-1.45$ \\
\hline Total Indirect cost per visit & 227 & 0.21 & 15.65 & $2.07(175.10)$ & $1.76-2.39$ \\
\hline Total cost per visit & 227 & 0.86 & 73.08 & $13.31(891.80)$ & $11.70-14.93$ \\
\hline Mean Visit per annum (approx) & 227 & 2 & 24 & $7.70(4.50)$ & $7.11-8.29$ \\
\hline Mean Visit per annum ( Public sector) & 76 & 2 & 12 & $5.01(2.74)$ & $4.39-5.63$ \\
\hline Mean Visit per annum ( Private sector) & 151 & 2 & 24 & $9.19(4.62)$ & $8.45-9.93$ \\
\hline
\end{tabular}

Note: US\$1 1 Nepalese Rupees (NRs.) 72

Direct cost per visit was found to be $289 \%$ higher in private sector outpatient clinics than in public sector. Total cost per visit, direct cost per month, total cost per month and total direct and indirect cost per annum were found to be higher for diabetic patients visiting private sector outpatient clinics (Table 2, 3 ).

\begin{tabular}{|c|c|c|c|c|c|c|c|c|c|c|}
\hline \multirow{2}{*}{$\begin{array}{l}\text { Cost } \\
\text { variables }\end{array}$} & \multicolumn{5}{|c|}{ Public sector } & \multicolumn{5}{|c|}{ Private sector } \\
\hline & $\mathrm{N}$ & Min. & Max. & Mean (SD) & $\begin{array}{l}95 \% \mathrm{Cl} \\
\text { for Mean }\end{array}$ & $\mathrm{N}$ & Min. & Max. & Mean SD & $\begin{array}{l}95 \% \mathrm{Cl} \text { for } \\
\text { Mean }\end{array}$ \\
\hline $\begin{array}{l}\text { Direct cost } \\
\text { per visit }\end{array}$ & 76 & 0.42 & 13.91 & $3.85(226.90)$ & $\begin{array}{r}3.14 \\
-4.56\end{array}$ & 151 & 3.89 & 72.08 & $\begin{array}{r}14.97 \\
(872.70)\end{array}$ & $13.04-16.90$ \\
\hline $\begin{array}{l}\text { Indirect } \\
\text { cost per } \\
\text { visit }\end{array}$ & 76 & 0.21 & 7.80 & 1.28 (89.90) & $0.99-1.56$ & 151 & 0.21 & 15.65 & $\begin{array}{r}2.47 \\
(199.10)\end{array}$ & 2.03- 2.91 \\
\hline $\begin{array}{l}\text { Total cost } \\
\text { per visit }\end{array}$ & 76 & 0.88 & 16.15 & $5.09 \quad(253)$ & $4.30-5.88$ & 151 & 4.38 & 73.08 & $\begin{array}{r}17.45 \\
(948.20)\end{array}$ & $15.35-19.55$ \\
\hline $\begin{array}{l}\text { Total } \\
\text { direct cost } \\
\text { per month }\end{array}$ & 76 & 3.13 & 80.13 & $\begin{array}{r}18.52 \\
(1082.90)\end{array}$ & $\begin{array}{r}15.13- \\
21.90\end{array}$ & 151 & 8.54 & 161.11 & $\begin{array}{r}48.27 \\
(2224.30)\end{array}$ & $42.33-53.19$ \\
\hline $\begin{array}{l}\text { Total cost } \\
\text { per month }\end{array}$ & 76 & 3.56 & 80.34 & $\begin{array}{r}19.72 \\
(1090.80)\end{array}$ & $\begin{array}{r}16.31- \\
23.12\end{array}$ & 151 & 9.03 & 166.24 & $\begin{array}{r}50.83 \\
(2285.80)\end{array}$ & $45.76-55.86$ \\
\hline $\begin{array}{l}\text { Total } \\
\text { direct cost } \\
\text { per annum }\end{array}$ & 76 & 25.50 & 961.67 & $\begin{array}{r}195.34 \\
(13360.80)\end{array}$ & $\begin{array}{r}153.62- \\
237.05\end{array}$ & 151 & 60.67 & 1933.33 & $\begin{array}{r}543.73 \\
(27552.60)\end{array}$ & $\begin{array}{l}482.69- \\
604.77\end{array}$ \\
\hline
\end{tabular}


Shrestha et al. Cost of Diabetes Mellitus Care among Patients attending selected Outpatient Clinics

\begin{tabular}{|c|c|c|c|c|c|c|c|c|c|c|}
\hline $\begin{array}{l}\text { Total } \\
\text { indirect } \\
\text { cost per } \\
\text { annum }\end{array}$ & 76 & 0.83 & 93.67 & $8.06(1014.60)$ & $4.89-11.22$ & 151 & 0.72 & 187.83 & $\begin{array}{r}25.09 \\
(2468.20)\end{array}$ & $19.62-30.56$ \\
\hline $\begin{array}{l}\text { Total cost } \\
\text { per annum }\end{array}$ & 76 & 27.50 & 964.17 & $\begin{array}{l}201.56 \\
(13482.40)\end{array}$ & $\begin{array}{r}159.46- \\
243.66\end{array}$ & 151 & 61.89 & 1994.83 & $\begin{array}{r}568.82 \\
(28561.50)\end{array}$ & 505.54-632.09 \\
\hline $\begin{array}{l}\text { Monthly } \\
\text { income }\end{array}$ & 76 & 41.67 & 69.45 & $\begin{array}{r}165.83 \\
(10167.70)\end{array}$ & $\begin{array}{r}134.08- \\
197.58\end{array}$ & 151 & 63.89 & 2083.33 & $\begin{array}{r}402.96 \\
(28654.10)\end{array}$ & $339.49-466.45$ \\
\hline $\begin{array}{l}\text { Household } \\
\text { income }\end{array}$ & 76 & 83.33 & 833.33 & $\begin{array}{r}276.90 \\
(12074.60)\end{array}$ & $\begin{array}{r}239.19- \\
315.60\end{array}$ & 151 & 83.33 & 2083.33 & $\begin{array}{r}604.17 \\
(24500.60)\end{array}$ & $549.89-658.44$ \\
\hline
\end{tabular}

Note: US\$ $1=$ Nepalese Rupees (NRs.) 72. Public sector refers to an outpatient clinic based in a government owned health institution and private sector refers to an outpatient clinic based in privately owned health institution.

\begin{tabular}{|lccccc|}
\hline \multicolumn{7}{l}{$\begin{array}{l}\text { Table 3. Cost variable (in US\$) associated with direct and indirect cost per month and per annum of the respon- } \\
\text { dents. }\end{array}$} & $\mathrm{N}$ & Min. & Max. & Mean (SD) & $95 \% \mathrm{Cl}$ for $\mathrm{Mean}$ \\
\hline Cost Variables & 227 & 3.13 & 161.11 & $38.31(2167.50)$ & $34.39-42.22$ \\
Total direct cost per month & 227 & 3.56 & 166.24 & $40.41(2232.70)$ & $36.38-44.45$ \\
Total cost per month & 227 & 25.50 & 1933.33 & $427.08(26530.20)$ & $379.15-475.02$ \\
$\begin{array}{l}\text { Total direct cost per annum } \\
\text { Total indirect cost per }\end{array}$ & 227 & 0.72 & 187.83 & $19.31(2172.90)$ & $15.46-23.31$ \\
$\begin{array}{l}\text { annum } \\
\text { Total cost per annum }\end{array}$ & 227 & 27.50 & 1994.83 & $445.86(27534.90)$ & $396.11-495.61$ \\
\hline
\end{tabular}

Note: US\$1= Nepalese Rupees (NRs.) 72

\begin{tabular}{|c|c|c|c|c|}
\hline Wealth quintile & $\begin{array}{l}\text { Mean direct cost } \\
\text { per month }\end{array}$ & $\begin{array}{l}\text { Mean monthly income in } \\
\text { Rs. (\% of monthly income) }\end{array}$ & $\begin{array}{l}\text { Mean household } \\
\text { income per month }\end{array}$ & $\begin{array}{l}\text { \% of household } \\
\text { income }\end{array}$ \\
\hline $\begin{array}{l}\text { Lowest Quintile } \\
\text { (<US\$ 417) }\end{array}$ & 23.81 & $154.35(15.40 \%)$ & 238.26 & $9.90 \%$ \\
\hline $\begin{array}{l}\text { Second Quintile } \\
\text { (US\$ 417-US\$833) }\end{array}$ & 47.22 & $323.47(14.60 \%)$ & 564.57 & $8.30 \%$ \\
\hline $\begin{array}{l}\text { Third Quintile } \\
\text { (US\$833-US\$1250) }\end{array}$ & 50.67 & $579.75(8.70 \%)$ & 899.89 & $5.60 \%$ \\
\hline $\begin{array}{l}\text { Fourth Quintile } \\
\text { (US\$1250-US\$1667) }\end{array}$ & 49.43 & $1510.42(3.20 \%)$ & 1510.42 & $3.20 \%$ \\
\hline $\begin{array}{l}\text { Highest Quintile } \\
\text { ( } \geq \text { US\$1667) }\end{array}$ & 109.72 & $1875.00(5.80 \%)$ & 1875.00 & $5.80 \%$ \\
\hline
\end{tabular}

Note: US\$ $1=$ Nepalese Rupees (NRs) 72

The calculation of the quintile was done based on the maximum value of household income per month. Household income was taken as the basis for categorization of the respondents into wealth quintile as individual income was bound to devaluate the treatment seeking capability of the housewives, pensioners and other respondents not working currently with higher household income. 
A weighted Least Square Analysis was performed which suggested that there is a linear and significant relationship between the three variables-household income per month(Hincome), duration of DM(dura), number of co- morbidities (Nocom) and total direct cost per annum (td). The weighted variable was household income per month. The model equation obtained was as follows:

$\mathrm{td}=.220 \times$ dura $+.186 \times$ Nocom $+.528 \times$

Hincome -4129.515

The equation was found to be significant at $95 \%$ level of significance. The equation estimated that for every one year increment in the duration of DM, total direct cost per year increases by US\$ 3.05 holding other predictor variables constant. Similarly, when there is a unit increase in the number of co morbidities that the patient is suffering, total direct cost per year increases by US\$ 2.58 holding other factors constant. Furthermore, holding other factors constant, a unit increase in household income (one unit=US\$ $13.88=$ NRs. 1000 ) was estimated to increase the total direct cost per year by US\$ 7.33. Since the maximum duration of illness among the patientswas found to be 20 years the predictive power of equation would be limited to diabetic patient with up to 20 years of illness.

The results of the study also revealed that total direct cost per annum for a diabetic patient with 16 to 20 years of illness was approximately $161 \%$ higher than the diabetic patient with illness duration of one to five year (Figure 1). The cost figure for the diabetic patient placed at the highest wealth quintile was six times the amount for diabetic patient belonging to lowest wealth quintile (Table 4).

\section{DISCUSSION}

The economic burden of DM is enormous in the world. DM has turned out to become a major public health problem because a great proportion of the healthcare expenditure has been spent on the treatment of its associated morbidity and mortality. Once DM develops it is very costly to manage because of its chronic nature and severity of complications.

The costly nature of the disease could be better explained by the fact that people with DM have frequent and intensive encounters with the health system and are heavy lifetime users of health resources. ${ }^{9,10}$ People with DM have higher use of hospital inpatient care, outpatient and physician office visits, emergency visits, nursing facility stays, home health visits, visits to other health professionals, and prescription drug and medical supply use more than their peers without DM. ${ }^{11}$ People with DM are at an increased risk of developing long term complication such as amputation, retinopathy, cardiovascular disease, neuropathy, nephropathy and peripheral vascular disease..$^{3,4}$ About $70 \%$ of the DM related costs are attributed to its complications. ${ }^{6} \mathrm{DM}$ complications account for $60 \%$ of the DM related health care costs and almost $80 \%$ to $90 \%$ of the indirect cost. Overtime diabetic individuals do learn to live with the resultant complications; however comorbidities that come with the disease and routine health monitoring requirements ensure that diabetic patients are more than twice more costly to treat than non-diabetic ones. ${ }^{8}$

Thus such prolonged and routine use of health resources and inherent morbidities provide a valid and logical basis for certifying high cost considerations in DM care. The economic burden of DM is not only related to health care costs but also to indirect costs caused by loss of productivity from disability and premature mortalityor lost economic opportunity. ${ }^{1,3,4}$

DM being a chronic illness tends to affect older age groups. The majority of respondents $(70 \%)$ in this study belonged to the age group of $46-60$ years. According to Mohan et al. ${ }^{1}$ DM seems to have written a different script for the developing world where majority of the diabetics belong to the age group of 45 to 64 years which happens to be the economically productive age group and more often affects the active member of the family, the principal breadwinner,pushing the whole family into a vicious cycle of worsening health related condition and poverty. ${ }^{6}$

With regards to the cost variables, the direct cost figures were found to be higher than the indirect cost figures. The direct cost figures for per visit, per month and per annum were calculated taking into consideration various cost components. However, the indirect cost figures were calculated based only on lost time which was converted into lost income based on wage rate hour which might have underestimated the indirect cost figures. The average monthly and household income of the respondents attending the private sector was found to be higher than the respondents attending the public sector. A higher income increases the ability to spend more on health care which means those who visited private clinics could afford comparatively better but more expensive services provided. 


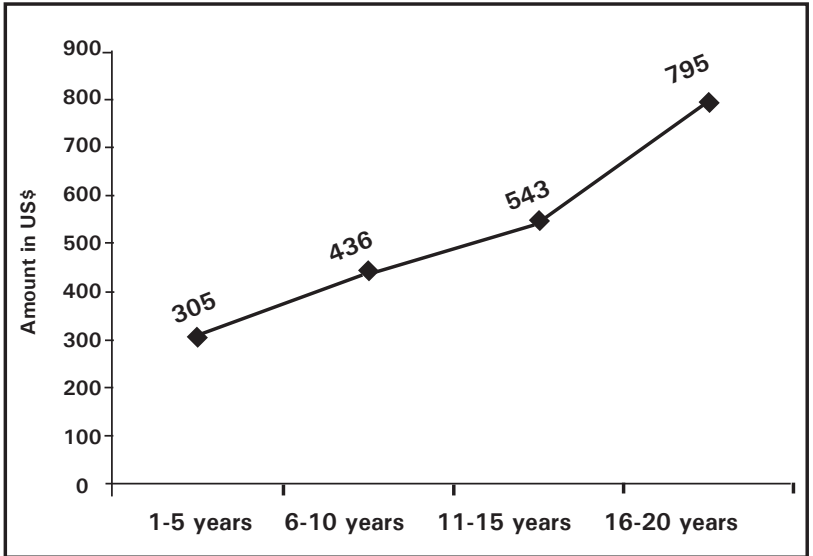

Figure 1. Mean value of total direct cost per annum (in US\$) among respondents with the respective duration of illness.

In this study housewife was also considered as a profession and the wage rate of the housewives was estimated using the minimum wage rate (US\$ 64) of Nepal in $2009 .{ }^{7}$ The concept of fixing the wage rate for the housewives was adapted from a study in Karachi, Pakistan. ${ }^{6}$ However, the objective of the study was not to devaluate the importance of housewives by fixing payment equal to the least paid salary in the country. It was used only for the sole purpose of calculating the indirect cost incurred to a housewife. By doing so the study respects the valuable time that housewives put into the care and management of illness in addition to carrying out chores.

No any similar published study in the country could be obtained for drawing comparisons on cost figures presented by the study. It was also not possible to compare with cost figures published in studies from other countries due to differences in exchange rates of currency between countries. Comparisons were also difficult because cost figures are largely dependent upon service charges, subsidies, quality of health care services and mode of payment which are country specific and may vary from one country to another. In the current context there are very few published studies that have estimated the cost of illness of DM in the country. Consequently, the cost burden of the illness is subject only to speculations and estimations. We are convinced that this study will highlight the cost burden of DM care and encourage extensive studies on the issue.

\section{CONCLUSIONS}

There is a higher cost burden on diabetic patients visiting the private sector outpatient clinics compared to those visiting public sector outpatient clinic. During the course of the study it was also known that patients are subjected to some form of pain, anxiety and depression associated with the illness which is of significant importance in estimation of indirect cost. Future studies should be designed in such a way that they produce more accurate estimates of per visit cost figures. This can be achieved if calculations are not just based on a single visit but on an average of at least two or as far possible three visits occurring over a period of six months. Thus an average of cost of all the visits would provide more valid information.

\section{REFERENCES}

1. Mohan V, Madan Z, Jha R, Deepa R, Pradeepa R. DM-Social and Economic Perspectives in the New Millenium. International Journal of $\mathrm{DM}$ in Developing Countries. 2004;24:29-35.

2. International DM Federation. The Economic Impacts of DM. [Online]. 2010 [Cited 2010 Mar 29]. Available from: URL:http://archive.DMatlas.org/content/ economic-impacts-DM

3. Grover S, Avasthi A, Bhansali A, Chakrabarti S, Kulhara P. Cost of ambulatory care of DM mellitus: a study from north India. Postgraduate Medical Journal. 2005;81:391-5.

4. Barcelo' A, Aedo C, Rajpathak S, Robles S. The cost of DM in Latin America and the Caribbean. Bulletin of the World Health Organization. 2003;81(1):19-27.

5. Chale SS, Swai ABM, Mujinja PGM, Mclarty DG. Must DM be a fatal disease in Africa? Study of costs of treatment. BMJ. 1992;304:1215-8.
6. Khowaja LA, Khuwaja AK, Cosgrove P. Cost of DM care in outpatient clinics of Karachi, Pakistan. BMC Health Service Research. 2007;7:189.

7. United States Department of State. 2008 Human Rights Report: Nepal [Online]. 2008 [Cited 2010 Feb 29]. Available from: URL:http://www.state.gov/j/drl/rls/hrrpt/2008/ sca/119138.htm

8. Rayappa, P.H., Raju, K.N.M., Kapur, A., Bjork, S., Sylvest, C. and Kumar, K.M.D. Economic Cost of DM Care: The Bangalore Urban District DM Study. The International Journal of DM in Developing Countries. 1999;19:87-97.

9. World Health Organization. DM [Online]. 2010 [Cited 2010 Mar 29]. Available from: URL:http://www.who.int/mediacentre/ factsheets/fs312/en/

10. Epidemic of DM in Urban Nepal - Time to Act [Editorial]. J Nepal Med Assoc. 2003;42:224-9.

11. Dall T, Mann S E, Zhang Y, Martin J, Chen Y, Hogan P. Economic Cost of DM in the US in 2007. DM Care. 2008 Mar;31(3):596-615. 